УДК 614.274:618.177-089.888:658.843(477)

DOI https://doi.org/10.11603/2312-0967.2019.3.10405

\title{
АНАЛІЗ РЕАЛЬНИХ ДАНИХ ПРИЗНАЧЕНЬ ЛІКАРСЬКИХ ЗАСОБІВ У ПРОТОКОЛАХ СТИМУЛЯЦІЇ ПРИ ДОПОМІЖНИХ РЕПРОДУКТИВНИХ ТЕХНОЛОГІЯХ В УКРАЇНІ
}

\author{
Х.-О. Я. Стасів, О. М. Заліська, Н. М. Максимович \\ Львівський національний медичний університет імені Данила Галицького \\ khrystyna.stasiv6545@gmail.com
}

ІНФОРМАЦІЯ

Надійшла до редакції / Received 05.06.2019

Після доопрацювання / Revised: 11.06.2019

Прийнято до друку / Accepted: 14.06.2019

\section{Ключові слова:}

допоміжні репродуктивні

технології;

ABC/VEN-аналіз;

короткий протокол стимуляції; довгий протокол стимуляції; безпліддя.
АНОТАЦІЯ

Мета роботи. Вивчити реальні дані призначень лікарських засобів і витрат на них у протоколах стимуляції при допоміжних репродуктивних технологіях (ДРТ) на основі ретроспективного аналізу медичних карт пацієнток у державному та приватному медичних центрах з ДРТ.

Матеріали і методи. Аналіз частоти призначень, ранжування за витратами та ступенем важливості препаратів провели з допомогою ABC, VEN - аналізу та інтегрованого частотного / ABC, VEN- аналізу.

Результати й обговорення. Частотний аналіз показав, що найбільш призначуваними препаратами за частотою у протоколах стимуляції жінок, які включені у Державну Програму лікування, були: хоріонічний гонадотропін, кислота ацетилсаліцилова, ганірелікс; у приватному медичному центрі для жінок із довгим чи коротким протоколом лікування - полівітаміни 3 мікроелементами, прогестерон, кислота ацетилсаліцилова. Таким чином, структура призначень ЛЗ у протоколах стимуляції овуляції жінкам у приватному центрі показує, що найвищу частоту призначень мають вітамінно-мінеральні комплекси, які не включені у Протоколи лікування. Ми встановили, що вартість курсу лікування на початку 2019 року (оптові ціни Л3) у приватній структурі для жінки коротким протоколом стимуляції овуляції у середньому становить 15 237,48 грн, при використанні довгого протоколу становлять 22 793,86 грн, тобто на 33,2 \% вищі витрати для пацієнтки.

Висновки. Встановлено, що при використанні довгого протоколу стимуляції 77 \% витрат припадає на Л3, які є життєво необхідними при ДРТ, 16 \% - на основні (essential) Л3 та $7 \%$ - на другорядні Л3. Для короткого протоколу стимуляції овуляції 73 \% витрат припадає на Л3, які належать до категорії «V», 10 \% - для категорії «Е» та майже 17 \% - на другорядні Л3, тому виявлено напрями оптимізації призначень у цих схемах ДРТ.

Встановлено, що у довгих та коротких протоколах стимуляції овуляції у приватному центрі використовуються Л3, які належать до другорядних, що вимагає оптимізації призначень для раціональності витрат. Перспективним $€$ фрармакоекономічний аналіз схем стимуляції за показниками «витратиесрективність» для визначення економічно вигідних препаратів на курс лікування.

ISSN 2312-0967. Pharmaceutical review. 2019. № 3 
Вступ. В Україні, за даними державних статистичних звітів, у 2012 році зареєстровано вперше випадків жіночого безпліддя 12 579, а чоловічого - 3712, то в 2017 р. було зареєстровано 38168 випадків жіночого безпліддя і 10945 випадків чоловічого безпліддя, поширення безпліддя за останні роки зросло в 3 рази, тому збільшується потреба у допоміжних репродуктивних технологіях (ДРТ - Assisted Reproductive Technology) [1]. Відповідно до наказу МОЗ України від 09.09.2013 р. № 787 «Про затвердження порядку застосування допоміжних репродуктивних технологій в Україні» ДРТ - це методики лікування безпліддя, за яких маніпуляції з репродуктивними клітинами, окремі або всі етапи підготовки репродуктивних клітин, процеси запліднення і розвитку ембріонів до перенесення їх у матку пацієнтки здійснюються в умовах in vitro [2]. Такі технології дозволяють покращувати показники народжуваності, що актуально для цілої нації. Так, в Україні на початку 2017 року коесріцієнт народжуваності дорівнював 1,47, що означає низький рівень [3]. За міжнародними даними після появи на світ першої дитини (Луїзи Браун у 1978 році) у світі за допомогою ДРТ народилось більше 8 млн дітей [4]. Результати дослідження, які опубліковані у 2018 р. вказують, що за допомогою ДРТ у європейських країнах середній коесіцієнт народжуваності збільшився 3 1,3 \% у 1997 р. до 2,4 \% - 2011 р.

Відповідно до положень Європейської конвенції про права людини, одним з найважливіших прав людини $є$ право на виліковування від безпліддя із застосуванням всіх засобів, якими володіє сучасна репродуктивна медицина [5].

В Україні зростає закупівля лікарських засобів (ЛЗ) за кошти Державного бюджету. Наказом МОЗ України від 09.10.2018 р. № 1838 «Про Розподіл лікарських засобів для забезпечення проведення лікування безплідності жінок методами допоміжних репродуктивних технологій, закуплених за кошти Державного бюджету України на 2018 рік» затверджено дві торгові назви Лз для забезпечення проведення лікування безпліддя жінок методами ДРТ: Фоліграф ТМ та Пропофол-Ново для п'яти державних закладів, які проводять ДРТ [6]. Також в Україні було розглянуто Пропозиції до номенклатури ЛЗ, що закуповуватимуться за бюджетні кошти у 2019 році за бюджетною програмою у частині «Закупівля медикаментів та дрібного лабораторного інвентарю для забезпечення проведення лікування безплідності жінок методами допоміжних репродуктивних технологій». До бюджетної програми включено такі $8 \mathrm{MHН:} \mathrm{хоріонічний} \mathrm{гона-}$ дотропін альфа, фролітропін-альфра 75 МО та $300 \mathrm{MO}$, фолітропіну бета, пропофол, трипторелін, менотропін та ганірелікс [7].

Мета роботи - провести збір та аналіз призначень лз за даними протоколів стимуляції овуляції для настання вагітності за допомогою ДРТ на базі державного і приватного медичних центрів та оцінити реаль-

ну практику призначень лЗ з проведенням ABC/VENаналізу.

Матеріали і методи. Об'єки дослідження: електронна база даних протоколів стимуляції (короткі та довгі протоколи у програмному забезпеченні Доктор ELEKS) пацієнток, які проходили лікування з 2017 по 2018 роки у ПП «Медичний центр Медікавер» у м. Львові. Дана установа подає дані результатів використання ДРТ у «Інформаційно-статистичний довідник про допоміжні репродуктивні технології в Україні», що свідчить про хороші результати роботи [8]. Також ми вивчали базу даних протоколів стимуляції Державного закладу «Прикарпатський центр репродукції людини» (ДЗ ПЦРЛ) м. Івано-Франківськ. Аналіз усіх протоколів виконано у програмі Microsoft Excel 10.

Здійснено аналіз призначень ЛЗ у протоколах стимуляції, для визначення вартості курсу лікування використовували оптові ціни на Л3, які розмішені на сайті «Еженедельник АПТЕКА», станом на 01 квітня 2019 року.

У нашій методиці категорії VEN-аналізу формували за такими критерієми: група « $-л 3$, які входять до рекомендацій NICE Guidance «Fertility problems: assessment and treatment», 2017 [9]; наказу МО3 України від 09.09.2013 р. № 787 «Про затвердження Порядку застосування допоміжних репродуктивних технологій в Україні» [2] та Національного переліку основних лікарських засобів і виробів медичного призначення, затвердженого Постановою КМ України від 13.12.2017 р. № 1081 [10]; група «Е» - Л3, які ввійшли лише в один з вказаних документів; група «N»другорядні ЛЗ, які не входять у вищенаведені документи.

Проведено аналіз вікового критерію пацієнток 3 використанням методів описової статистики, розподіл параметричних показників у вибірці перевіряли на відповідність закону нормальності (Гаусівський розподіл).

Результати й обговорення. В Україні діє Державна Програма надання першої спроби ДРТ за бюджетні кошти у жінок із абсолютним безпліддям (згідно 3 наказом МО3 України від 29.11.2004 р. № 579 «Про затвердження Порядку направлення жінок для проведення першого курсу лікування безплідності методами допоміжних репродуктивних технологій за абсолютними показаннями за бюджетні кошти») [11]. Станом на 01.01.2018 рік в Україні за Державною Програмою проліковано 2849 жінок та народилося 778.

Відповідно до Державної Програми перший курс лікування безпліддя методами ДРТ жінкам у віці 19 - 40 років здійснюється за абсолютними показаннями: безплідність трубного походження нормогонадотропна: відсутність або повна непрохідність обох маткових труб; сурогатне материнство, якщо у хворої безплідність маткового походження, пов'язана з від-

ISSN 2312-0967. Фармацевтичний часопис. 2019. № 3 
сутністю матки, аномаліями розвитку матки, синехіями у порожнині матки [11]

В Україні за Державною Програмою працюють п'ять спеціалізованих медичних закладів, серед яких «Прикарпатський центр репродукції людини» (ПЦРЛ) у м. Івано-Франківськ [12]. 32004 по 2018 рр. у даному центрі було надано першу спробу лікування безпліддя за допомогою ДРТ 2276 жінкам, з них 1193 (45 \%) - стали вагітними. Пацієнтами ПЦРЛ можуть бути жителі Івано-Франківської, Закарпатської, Волинської, Чернівецької, Житомирської, Рівненської, Тернопільської та Львівської областей, щорічно проводиться 140 - 150 циклів ДРТ. ПЦРЛ щотижнево звітує щодо залишку Л3, закуплених за кошти Державного бюджету України.

Проведено ABC/VEN-аналіз 17-ти протоколів стимуляції овуляції для настання вагітності з допомогою ДРТ у ПЦРЛ у м. Івано-Франківськ за 2018 рік, які становлять 10 \% від загальної кількості протоколів, що дозволяє визначити тенденції призначень. Результати наведено у таблиці 1.

Проведений ABC/VEN-аналіз протоколів стимуляції овуляції для жінок, які включені у Державну Програму лікування показав, що у групі А 76 \% витрат припадає для життєво необхідних та важливих лз. У групі В майже 8 \% витрат припадає на групу «V» та $13 \%$ - на групу «Е». У групі C - менше відсотка (0,31 \%) витрат припадає на Л3 життєво необхідні та 3 \% витрат на важливі Л3. Другорядних Л3 не було включено у протоколи лікування.

Наступним етапом був аналіз реальних даних приймання Л3 за даними протоколів стимуляції овуляції для настання вагітності з допомогою ДРТ у приватному медичному центрі. Станом на початок 2019 р. в Україні фрункціонує більше 50 клінік. Об'єктом нашого вивчення були протоколи стимуляції овуляції у Медичному центрі Медікавер, м. Львів, який системно подає статистичну інформацію до Українського реєстру. Досліджена сукупність становила 73 протоколи, які включають 13 довгих та 60 коротких протоколів за 2017-2018 роки.

Короткий протокол відповідає тривалості менструального циклу жінки, а сама програма починається відразу з стимулюючого етапу, що припадає на 3 день місячного циклу. Довгий протокол починається 321 дня поточного циклу і відрізняється від короткого тим, що протягом 2-3 тижнів яєчники жінки піддаються потужній гормональній стимуляції, в результаті чого в одному циклі дозріває відразу кілька яйцеклітин.

Підтвердження репрезентативності вибірки жінок проводилося на основі вікового критерію. При проведенні аналізу ми обирали вікові межі від 15 до 49 років, оскільки такий вік, за даними ВООЗ, вважається фертильним для жінки [13]. Одержані результати наведені у вигляді діаграми на рисунку 1, які підтвердили наявність нормального (Гаусівського) розподілу:

- середнє арифрметичне значення, наближене до медіального значення $(32,67)$.

- справдилося правило «трьох сигм»: всі пацієнтки увійшли в межі довірчого інтервалу: $33.7 \pm 3 * 4.2$ (від 21.1 до 46.3) Ме (25 \%; 75 \%) = 33 (30; 35).

Встановлено, що загальна сукупність лз у довгому протоколі стимуляції овуляції у Медичному центрі «Інтерсоно Medicover Group» становила 32 торгові назви л3, що відповідало 19 МНН. Оцінку практики призначень ЛЗ проведено за допомогою ABC/VEN- аналізу, результати наведені у таблицях 2 та 3.

\section{Таблиця 1}

Результати ABC/VEN-аналізу протоколів стимуляції овуляції для жінок, які включені у Державну Програму лікування

\begin{tabular}{|c|c|c|c|c|c|c|}
\hline № 3/п & $\mathrm{MHH}$ & АТХ-код & $\begin{array}{c}\text { Кількість } \\
\text { призначень, } \\
\text { n }\end{array}$ & $\begin{array}{l}\text { Сума ви- } \\
\text { трат, грн }\end{array}$ & $\begin{array}{c}\text { Питома вага } \\
\text { витрат, \% }\end{array}$ & ABC/VEN аналіз \\
\hline 1 & Follitropin alfa & G03GA05 & 9 & 142819.74 & 41.69 & A/V \\
\hline 2 & Follitropin beta & G03GA06 & 5 & 118964.2 & 34.72 & $A / E$ \\
\hline 3 & Ganirelix & H01CC01 & 10 & 43881.11 & 12.81 & $\mathrm{~B} / \mathrm{E}$ \\
\hline 4 & $\begin{array}{l}\text { Human menopausal } \\
\text { gonadotropin }\end{array}$ & G03GA02 & 3 & 13271.14 & 3.87 & $B / V$ \\
\hline 5 & Triptorelin & L02AE04 & 5 & 13135.04 & 3.83 & $\mathrm{~B} / \mathrm{V}$ \\
\hline 6 & Chorionic gonadotrophin & G03GA01 & 17 & 8705.19 & 2.54 & $\mathrm{C} / \mathrm{E}$ \\
\hline 7 & Progesterone & G03DA04 & 8 & 1060.97 & 0.31 & $\mathrm{C} / \mathrm{V}$ \\
\hline 8 & Acetylsalicylic acid & B01AC06 & 14 & 418.44 & 0.12 & C/E \\
\hline 9 & Dexamethasone & $\mathrm{H} 02 \mathrm{AB} 02$ & 7 & 234.29 & 0.07 & C/E \\
\hline 10 & Estradiol & G03CA03 & 2 & 116.23 & 0.03 & C/E \\
\hline \multicolumn{3}{|l|}{ PAЗОМ } & 78 & 342606.35 & 100,0 & \\
\hline
\end{tabular}

ISSN 2312-0967. Pharmaceutical review. 2019. № 3 
Фармакоекономіка

Pharmacoeconomics

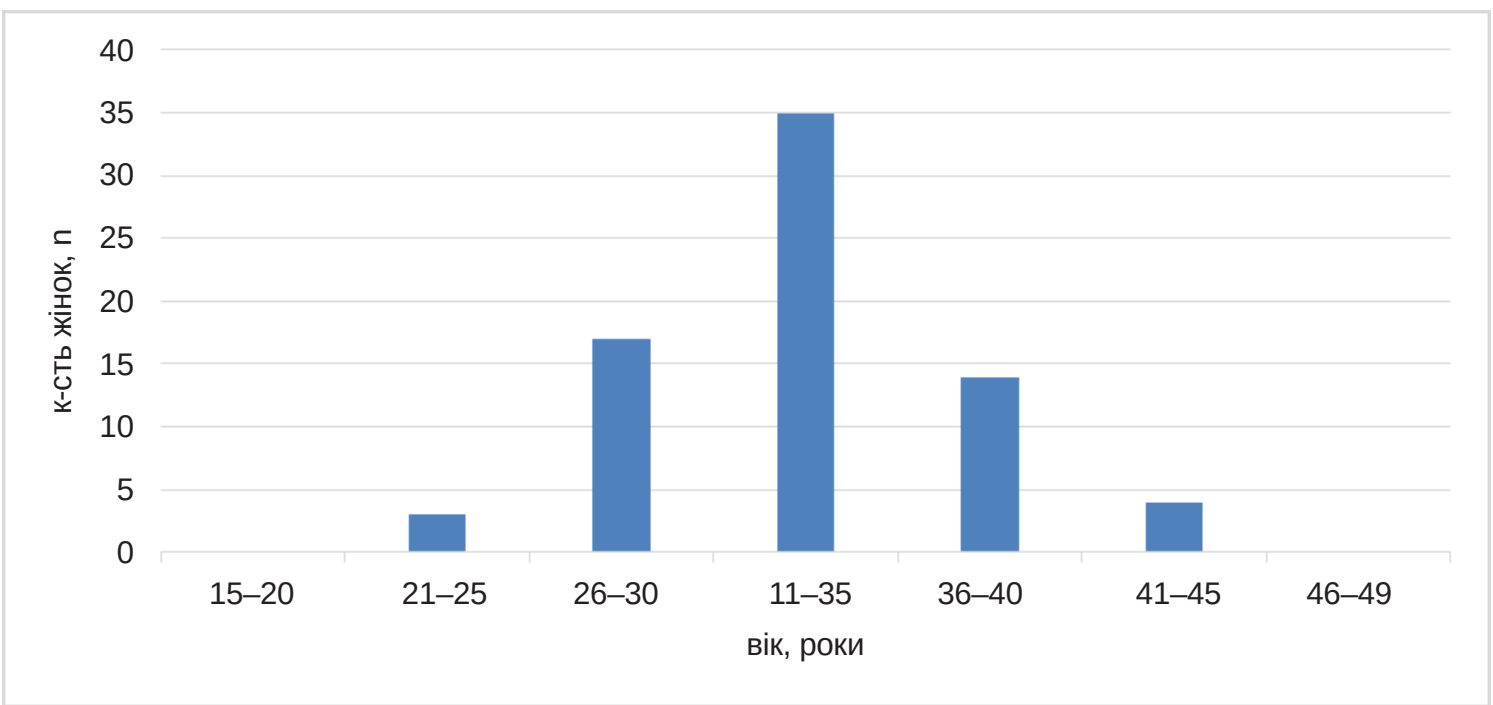

Рис. 1. Віковий розподіл пацієнток, які проходили лікування за допомогою ДРТ у медичному центрі за 2017-2018 рр.

\section{Таблиця 2}

Результати ABC/VEN-аналізу довгих протоколів стимуляції овуляції

\begin{tabular}{|c|c|c|c|c|c|c|}
\hline $\begin{array}{l}\text { № } \\
3 / \Pi\end{array}$ & $\mathrm{MHH}$ & АТХ-код & $\begin{array}{c}\text { Кількість } \\
\text { призна- } \\
\text { чень, n }\end{array}$ & $\begin{array}{l}\text { Сума ви- } \\
\text { трат, грн }\end{array}$ & $\begin{array}{c}\text { Питома } \\
\text { вага ви- } \\
\text { трат, \% }\end{array}$ & $\begin{array}{c}\text { ABC/VEN } \\
\text { аналіз }\end{array}$ \\
\hline 1 & Follitropin alfa & G03GA05 & 7 & 112833.92 & 38.08 & $\mathrm{~A} / \mathrm{V}$ \\
\hline 2 & $\begin{array}{l}\text { Human menopausal } \\
\text { gonadotrophin }\end{array}$ & G03GA02 & 9 & 79402.91 & 26.80 & $\mathrm{~A} / \mathrm{V}$ \\
\hline 3 & Triptorelin & L02AE04 & 9 & 20973.84 & 7.08 & $A / V$ \\
\hline 4 & Follitropin alfa/ Lutropin alfa & G03GA30 & 1 & 15896.88 & 5.36 & $A / E$ \\
\hline 5 & Corifollitropin alfa & G03GA09 & 2 & 14911.00 & 5.03 & $\mathrm{~B} / \mathrm{V}$ \\
\hline 6 & Follitropin beta & G03GA06 & 2 & 14286.46 & 4.82 & $\mathrm{~B} / \mathrm{E}$ \\
\hline 7 & Immunoglobulins, & J06B A02 & 1 & 13797.10 & 4.66 & $\mathrm{~B} / \mathrm{N}$ \\
\hline 8 & Chorionic gonadotropin & G03GA01 & 9 & 8166.15 & 2.76 & $\mathrm{~B} / \mathrm{E}$ \\
\hline 9 & Comb drug (polyvitamini) & A11E A & 62 & 4404.31 & 1.49 & $\mathrm{C} / \mathrm{N}$ \\
\hline 10 & Progesterone & G03DA04 & 24 & 3584.38 & 1.21 & $\mathrm{C} / \mathrm{V}$ \\
\hline 11 & Cetrorelix & $\mathrm{H} 01 \mathrm{CCO} 2$ & 1 & 3416.38 & 1.15 & $\mathrm{C} / \mathrm{E}$ \\
\hline 12 & Nadroparin calcium & B01АB06 & 2 & 1454.31 & 0.49 & $\mathrm{C} / \mathrm{E}$ \\
\hline 13 & Choriogonadotropin alfa & G03GA08 & 1 & 1389.66 & 0.47 & $\mathrm{C} / \mathrm{E}$ \\
\hline 14 & Estradiol & G03CA03 & 4 & 725.94 & 0.24 & $\mathrm{C} / \mathrm{E}$ \\
\hline 15 & Acetylsalicylic acid & B01AC06 & 15 & 544.71 & 0.18 & $\mathrm{C} / \mathrm{E}$ \\
\hline 16 & Enoxaparin sodium & B01AB05 & 1 & 216.32 & 0.07 & $\mathrm{C} / \mathrm{E}$ \\
\hline 17 & Methylprednisolone & $\mathrm{H} 02 \mathrm{AB} 04$ & 3 & 211.92 & 0.07 & C/E \\
\hline 18 & Folic acid & B03B B01 & 5 & 51.96 & 0.02 & $\mathrm{C} / \mathrm{E}$ \\
\hline 19 & Ethinylestradiol+Drosperinone & G03AA12 & 1 & 45.87 & 0.02 & $\mathrm{C} / \mathrm{N}$ \\
\hline \multicolumn{3}{|c|}{ PA3ОM } & 158 & 296314.02 & 100,0 & \\
\hline
\end{tabular}

Як видно з даних таблиці 2, групу А сорормували життєво необхідні та важливі ЛЗ, витрати на які становлять 77 \%. У групі В 5 \% витрат припадає на ЛЗ 3 категорії «V», 8 \% витрат належить до категорії «Е» та майже 5 \% - на другорядні лз при дРТ. У групі С $1 \%$ витрат припадає на Л3 з категорії життєво необхідні, 3 \% витрат - для важливих ЛЗ та майже 2 \% на другорядні ЛЗ.

ISSN 2312-0967. Фармацевтичний часопис. 2019. № 3 
Таблиця 3

Результати ABC/VEN-аналізу коротких протоколів стимуляції овуляції

\begin{tabular}{|c|c|c|c|c|c|c|}
\hline $\begin{array}{l}\text { № } \\
3 / \Pi\end{array}$ & $\mathrm{MHH}$ & АТХ-код & $\begin{array}{c}\text { Кількість } \\
\text { призначень, } \\
n\end{array}$ & $\begin{array}{l}\text { Сума ви- } \\
\text { трат, грн }\end{array}$ & $\begin{array}{c}\text { Питома } \\
\text { вага ви- } \\
\text { трат, \% }\end{array}$ & $\begin{array}{c}\text { ABC/VEN } \\
\text { аналіз }\end{array}$ \\
\hline 1 & Follitropin alfa & G03GA05 & 44 & 331389.10 & 36.13 & $A / V$ \\
\hline 2 & Ganirelix & $\mathrm{H} 01 \mathrm{CC} 01$ & 54 & 164554.00 & 17.94 & $A / V$ \\
\hline 3 & Immunoglobulins. & J06B A02 & 10 & 137971.00 & 15.04 & $\mathrm{~A} / \mathrm{N}$ \\
\hline 4 & Human menopausal gonadotrophin & G03GA02 & 16 & 104834.00 & 11.43 & $\mathrm{~A} / \mathrm{V}$ \\
\hline 5 & Cetrorelix & $\mathrm{H} 01 \mathrm{CC} 02$ & 19 & 52954.00 & 5.77 & $\mathrm{~B} / \mathrm{E}$ \\
\hline 6 & Follitropin beta & G03GA06 & 5 & 49888.00 & 5.44 & $\mathrm{~B} / \mathrm{V}$ \\
\hline 7 & Choriogonadotropin alfa & G03GA08 & 26 & 36131.00 & 3.94 & $\mathrm{~B} / \mathrm{E}$ \\
\hline 8 & Progesterone & G03DA04 & 90 & 9305.68 & 1.01 & $\mathrm{~B} / \mathrm{V}$ \\
\hline 9 & Comb drug (polyvitamini) & A11AA03 & 116 & 8215.00 & 0.90 & $\mathrm{C} / \mathrm{N}$ \\
\hline 10 & Triptorelin & L02AE04 & 21 & 5901.40 & 0.64 & $\mathrm{C} / \mathrm{V}$ \\
\hline 11 & БАД (Inofolik softgel; Dekristol D3) & БАД & 43 & 5286.10 & 0.58 & $\mathrm{C} / \mathrm{N}$ \\
\hline 12 & Colecalciferol & $\mathrm{A} 11 \mathrm{CC} 05$ & 51 & 3676.20 & 0.40 & $\mathrm{C} / \mathrm{N}$ \\
\hline 13 & Chorionic gonadotrophin & G03GA01 & 7 & 3584.50 & 0.39 & $\mathrm{C} / \mathrm{V}$ \\
\hline 14 & Acetylsalicylic acid & $\mathrm{B} 01 \mathrm{AC} 06$ & 82 & 1735.30 & 0.19 & $\mathrm{C} / \mathrm{E}$ \\
\hline 15 & Methylprednisolone & $\mathrm{H} 02 \mathrm{AB} 04$ & 44 & 1262.50 & 0.14 & $\mathrm{C} / \mathrm{E}$ \\
\hline 16 & Metformin & A10BA02 & 1 & 374.84 & 0.04 & $\mathrm{C} / \mathrm{E}$ \\
\hline 17 & Folic acid & В03В В01 & 59 & 184.30 & 0.02 & $\mathrm{C} / \mathrm{E}$ \\
\hline \multicolumn{3}{|c|}{ РА30M } & 688 & 917246.92 & 100,0 & \\
\hline
\end{tabular}

Отримані дані частотного ABC/VEN-аналізу коротких протоколів стимуляції овуляції показали, що групі А 66 \% витрати припадають на життєво необхідні Л3 та 15 \% витрат на Л3, які є другорядними при ДРТ. Групу В сорормували життєво необхідні та важливі Л3, витрати на які становлять $6 \%$ та $10 \%$ відповідно. У групі С 1 \% витрат припадає на Л3 з категорії «У», менше відсотка (0,39 \%) витрат належить до категорії «Е» та майже 2 \% - на другорядні лЗ. Зазначимо, що саме у цій групі опинились найбільш часто призначувані препарати, проте не усі з них (наприклад, полівітаміни) є доказово-обґрунтованими при ДРТ.

Проведений ABC/VEN-аналіз протоколів стимуляції овуляції показав розподіл Лз на групи та встановлено частоту призначень та витрат на Л3, які наведено у таблиці 4.

Встановлено, що лідерами за частотою призначень у протоколах стимуляції овуляції жінок були такі лЗ за МHH:

- за Державною Програмою - хоріонічний гонадотропін, кислота ацетилсаліцилова, ганірелікс;

- у приватному медичному центрі для жінок з довгим чи коротким протоколом лікування - полівітаміни з мікроелементами, прогестерон, кислота ацетилсаліцилова.

Таким чином, аналіз реальних даних призначень лЗ у протоколах стимуляції показав структуру та частоту використання препаратів, які, в основному, від- повідають протоколам ДРТ в Україні. Виявлено, що у довгих протоколах стимуляції використовуються ЛЗ, які належать до другорядних, що вимагає оптимізації призначень для раціональності витрат.

Обчислено, що витрати на курс лікування у 2019 р. (оптові ціни Л3) у приватній структурі для жінки за коротким протоколом стимуляції овуляції у середньому становили 15 237,48 грн, при використанні довгого протоколу - 22 793,86 грн, тобто на 33,2 \% вищі витрати для пацієнтки.

Перспективним $€$ фрармакоекономічний аналіз схем стимуляції за показниками «витрати-ефрективність» для визначення економічно вигідних препаратів на курс.

Висновки. 1. Статистичні дані про поширеність безпліддя в Україні свідчать про зростання в 3 рази за 2012-2017 рр., тому актуальним є використання допоміжних репродуктивних технологій (ДРТ), бо у світі за останні 40 років народилось уже близько 8 млн дітей з допомогою ДРТ.

2. Результати ABC-VEN аналізу протоколів стимуляції овуляції жінок, які включені до Державної програми лікування у медичному закладі Івано-Франківська підтвердили, що 76 \% витрат на Лз припадає на життєво необхідні та важливі Л3, а другорядні ЛЗ не призначають, що свідчить про раціональність призначень.

4. Встановлено, що у приватному медичному центрі при використанні довгого протоколу стимуляції

ISSN 2312-0967. Pharmaceutical review. 2019. № 3 
Фармакоекономіка

Pharmacoeconomics

Таблиця 4

Результати інтегрованого частотного ABC/VEN-аналізу лікарських призначень у протоколах стимуляції овуляції

\begin{tabular}{|c|c|c|c|c|c|c|}
\hline \multirow{2}{*}{ Група } & \multicolumn{3}{|c|}{ Частота призначень Л3, n (\%) } & \multicolumn{3}{|c|}{ Витрати на Л3 , грн ( \%) } \\
\hline & $\mathrm{V}$ & $E$ & $\mathrm{~N}$ & $\mathrm{~V}$ & $E$ & $\mathrm{~N}$ \\
\hline \multicolumn{7}{|c|}{ Державний заклад } \\
\hline A & $9(11.53)$ & $5(6.40)$ & - & $142819.74(41.68)$ & $\begin{array}{c}118964.20 \\
(34.72)\end{array}$ & - \\
\hline B & $8(10.25)$ & $10(12.82)$ & - & $26406.18(7.07)$ & $\begin{array}{l}43881.11 \\
(12.80)\end{array}$ & - \\
\hline $\mathrm{C}$ & $8(10.25)$ & $40(51.28)$ & - & $1060.97(0.30)$ & $9474.15(2.76)$ & - \\
\hline \multicolumn{7}{|c|}{ Приватний заклад } \\
\hline$A$ & $\begin{array}{c}25(15.82)^{1} \\
114(16.56)^{2}\end{array}$ & $\begin{array}{c}1(0.63)^{1} \\
-\end{array}$ & $10(1.45)^{2}$ & $\begin{array}{l}213210.67(71.95)^{1} \\
600777.10(62.49)^{2}\end{array}$ & $\begin{array}{c}15896.88(5.36)^{1} \\
-\end{array}$ & $\begin{array}{c}- \\
137971.00 \\
(15.04)^{2}\end{array}$ \\
\hline B & $\begin{array}{c}2(2.56)^{1} \\
95(13.80)^{2}\end{array}$ & $\begin{array}{l}11(6.96)^{1} \\
45(6.54)^{2}\end{array}$ & $\begin{array}{l}1^{1} \\
-\end{array}$ & $\begin{array}{l}14911.00(5.03)^{1} \\
89085.00(9.71)^{2}\end{array}$ & $\begin{array}{l}22452.61(7.57)^{1} \\
59193.68(6.45)^{2}\end{array}$ & $\begin{array}{c}13797.10(4.65)^{1} \\
-\end{array}$ \\
\hline C & $\begin{array}{l}24(15.18)^{1} \\
28(4.06)^{2}\end{array}$ & $\begin{array}{c}32(20.25)^{1} \\
186(27.03)^{2}\end{array}$ & $\begin{array}{l}63(39.87)^{1} \\
210(30.52)^{2}\end{array}$ & $\begin{array}{l}3584.38(1.20)^{1} \\
9485.90(1.03)^{2}\end{array}$ & $\begin{array}{l}8011.20(2.70)^{1} \\
3556.94(0.38)^{2}\end{array}$ & $\begin{array}{c}4450.18(1.50)^{1} \\
17177.30(1.87)^{2}\end{array}$ \\
\hline
\end{tabular}

Примітки: 1 - довгий протокол лікування; 2 - короткий протокол лікування.

77 \% витрат припадає на Л3, які є життєво необхідними при ДРТ, $16 \%$ - на важливі Л3, проте 7 \% - на другорядні ЛЗ. Для короткого протоколу стимуляції овуляції 73 \% витрат припадає на Л3, які належать до категорії «V», 10 \% - для категорії «Е» та майже
17 \% - на другорядні лз, тому виявлено напрями оптимізації призначень у цих схемах ДРТ.

Конфлікт інтересів: відсутній.

Conflicts of interest: authors have no conflict of interest to declare.

\title{
ANALYSIS OF REAL DATA OF DRUG PRESCRIPTIONS IN PROTOCOLS OF STIMULATION FOR ASSISTED REPRODUCTIVE TECHNOLOGIES IN UKRAINE
}

\author{
Kh.-O.Ya. Stasiv, O. M. Zaliska, N. M. Maksymovych \\ Danylo Halytsky Lviv National Medical University \\ khrystyna.stasiv6545@gmail.com
}

The aim of the work. Study the real data of prescribing drugs and their costs in stimulation protocols for ART on the basis of a retrospective analysis of patients' medical cards in public and private medical centers of ART. Materials and Methods. The analysis of the frequency of prescription, the ranking of costs and the degree of importance of drugs was carried out with $A B C$, VEN-analysis and integrated frequency/ABC, VEN-analysis.

Results and Discussion. Frequency analysis showed that the most prescribed drugs in frequency were in the protocols of stimulation of women, included in the State Program of treatment: chorionic gonadotrophin, acetylsalicylic acid, ganirelix. In the private medical center for women with a long or short protocols were multivitamins with minerals, progesterone, acetylsalicylic acid. Thus, the structure of ART prescribing protocols for stimulating ovulation for women in a private center showed that the highest frequency of appointments were vitamin and mineral complexes that are not included in the Treatment Protocols. We found that the cost of the treatment course in 2019 (using wholesale prices of drugs) in a private centre for a woman's short protocol for ovulation stimulation was $15237.48 \mathrm{UAH}$, for a long protocol was $22793.86 \mathrm{UAH}$, that is $33.2 \%$ higher costs for a patient.

Conclusions. It is established that when using a long protocol of stimulation, $77 \%$ of expenditures are spent on drugs that are vital in DRTs, $16 \%$ in important medicines and $7 \%$ non-essential medicines. Costs for the short protocol for stimulation of ovulation, $73 \%$ belong to the $\mathrm{V}$ category, $10 \%$ for the $\mathrm{E}$ category and almost $17 \%$ for the non-essential drugs, so the directions of optimization of appointments in these ART schemes was identified.

It was found that in long and short protocols of stimulation of ovulation in a private center used drugs, which belong to non-essential drugs, it requires optimization of allocations for rationality of costs. The prospective is a pharmacoeconomic

ISSN 2312-0967. Фармацевтичний часопис. 2019. № 3 
analysis of stimulation schemes based on cost-effectiveness indicators for determining cost-effective drugs for the course of treatment.

Key words: assisted reproductive technologies; ABC/VEN-analysis; short protocol of stimulation; long protocol of stimulation; infertility.

\title{
АНАЛИЗ РЕАЛЬНЫХ ДАННЫХ НАЗНАЧЕНИЙ ЛЕКАРСТВЕННЫХ СРЕДСТВ В ПРОТОКОЛАХ СТИМУЛЯЦИИ ПРИ ВСПОМОГАТЕЛЬНЫХ РЕПРОДУКТИВНЫХ ТЕХНОЛОГИЯХ В УКРАИНЕ
}

\author{
Х.-О. Я. Стасив, О. Н. Залиская, Н. М. Максимович \\ Львовский национальный медицинский университет имени Данила Галицкого \\ khrystyna.stasiv6545@gmail.com
}

Цель работы. Изучить реальные данные назначений лекарственных средств и расходов на них в протоколах стимуляции при применении вспомогательных репродуктивных технологий (ВРТ) на основе ретроспективного анализа медицинских карт пациенток в государственном и частном медицинских центрах с ВРТ.

Материалы и методы. Анализ частоты назначений, ранжирование по расходам и степени важности препаратов провели с помощью ABC, VEN-анализа и интегрированного частотного / ABC, VEN- анализа.

Результаты и обсуждение. Частотный анализ показал, что наиболее назначаемыми препаратами по частоте в протоколах стимуляции женщин, включенных в Государственную программу лечения были: хорионический гонадотропин, ацетилсалициловая кислота, ганиреликс; а в частном медицинском центре для женщин с длинными или короткими протоколом лечения - поливитамины с микроэлементами, прогестерон, ацетилсалициловая кислота. Таким образом, структура назначений лС в протоколах стимуляции овуляции женщинам в частном центре показывает, что самую высокую частоту назначений имеют витаминно-минеральные комплексы, которые не включены в Протоколы лечения. Нами установлено, что стоимость курса лечения в начале 2019 (оптовые цены ЛС) в частной структуре для женщины коротким протоколом стимуляции овуляции в среднем составляет 15237,48 грн, при использовании длинного протокола составляют 22 793,86 грн, таким образом на 33, 2 \% выше расходы для пациентки.

Выводы. Установлено, что при использовании длинного протокола стимуляции 77 \% расходов приходится на лс, которые являются жизненно необходимыми при ВРТ, 16 \% - на важные ЛС и 7 \% - на второстепенные лС. Для короткого протокола стимуляции овуляции 73 \% расходов приходится на ЛС, относящихся к категории «V», $10 \%-$ для категории «Е» и почти $17 \%$ - на второстепенные ЛС, таким образом выявлены направления оптимизации назначений в этих схемах ВРТ.

Выявлено, что в длинных и коротких протоколах стимуляции овуляции в частном центре используются лС, относящихся квторостепенным, что требует оптимизации назначений для рациональности расходов. Перспективным является фрармакоэкономический анализ схем стимуляции по показателям «затраты-эфрфективность» для определения экономически выгодных препаратов на курс лечения.

Ключевые слова: вспомогательные репродуктивные технологии; ABC / VEN-анализ; короткий протокол стимуляции; долгий протокол стимуляции; бесплодие.

\section{Список літератури}

1. Інорормаційно-статистичний довідник про допоміжні репродуктивні технології в Україні [Електронний ресурс]. - Режим доступу : http://www.uarm.org.ua/ materiali/natsionalnij-reestr-drt.html

2. ПрозатвердженняПорядку застосування допоміжних репродуктивних технологій в Україні : наказ МОЗ України від 09.09.2013 р. № 787 [Електронний ресурс]. - Режим доступу : https://zakon.rada.gov.ua/ laws/show/z1697-13

3. Таблиці народжуваності, смертності та очікуваної тривалості життя. - Статистичний бюлетень. - Державна служба статистики України. 2017 [Електронний ресурс]. - Режим доступу : http:// database.ukrcensus.gov.ua/PXWEB2007/ukr/publ_ new1/2017/BL1001_2017_02_born.pdf.
4. Norcross S. Eight million ART babies and counting. [Електронний ресурс]. - Режим доступу:https://www. bionews.org.uk/page_136862

5. The International Covenant on Civil and Political Rights and the strategic shift to forced disappearance / C.L. Payne // Journal of Human Rights Vol.15, 2016 No. 2. P. $163-188$.

6. Про Розподіл лікарських засобів для забезпечення проведення лікування безплідності жінок методами допоміжних репродуктивних технологій, закуплених за кошти Державного бюджету України на 2018 рік : наказ МО3 України від 09.10.2018 р. № 1838 [Електронний ресурс]. - Режим доступу : http://www.moz.gov.ua

7. Шоста частина проектів до номенклатури лікарських засобів, що закуповуватимуться у 2019 р. за

ISSN 2312-0967. Pharmaceutical review. 2019. № 3 
бюджетною програмою «Забезпечення методичних заходів окремих державних програм та комплексних заходів програмного характеру» [Електронний ресурс]. - Режим доступу : https://www.apteka.ua/article/4788551

8. Медичний центр Медікавер [Електронний ресурс]. Режим доступу : https://medicover.ua/uk

9. NICE Guidance Fertility problems: assessment and treatment [Електронний ресурс]. - Режим доступу: https://www.nice.org.uk/guidance/cg156/chapter/ Recommendations\#investigation-of-fertility-problemsand-management-strategies

10. Національний перелік основних лікарських засобів [Електронний ресурс]. - Режим доступу : http://moz.

\section{References}

1. Information and Statistical Manual on Assisted Reproductive Technologies in Ukraine. [Electronic resource]. Available from: http: //www.uarm.org.ua/materiali/natsionalnij-reestr-drt.html. Ukrainian.

2. Order of the Ministry of Health of Ukraine of 09.09.2013 No. 787 "On Approval of the Procedure for the Application of Assisted Reproductive Technologies in Ukraine". [Electronic resource]. Available from: http://www.moz. gov.ua. Ukrainian.

3. Birth rate, mortality and expected life expectancy. State Bulletin. State Statistics Service of Ukraine. 2017 [Electronic resource]. Available from: http://database. ukrcensus.gov.ua/PXWEB2007/en/publ_new1/2017/ BL1001 201702 born.pdf. Ukrainian.

4. Norcross S. Eight million ART babies and counting [Electronic resource]. Available from: www.bionews.org. uk/page_136862

5. Payne $\overline{C L}$. The International Covenant on Civil and Political Rights and the strategic shift to forced disappearance. Journal of Human Rights. 15, 2016;15(2): 163188.

6. Order of the Ministry of Health of Ukraine dated 09.10.2018, No. 1838 "On the Distribution of Medicines for the Provision of Treatment of Infertility of Women by Methods of Assisted Reproductive Technologies Purchased with the State Budget of Ukraine for 2018". Available from: http://www.moz.gov.ua. Ukrainian.

7. Sixth part of the projects to the nomenclature of medi- gov.ua/uploads/0/3799-nacperelic dodatok web.pdf

11. Про затвердження Порядку направлення жінок для проведення першого курсу лікування безплідності методами допоміжних репродуктивних технологій за абсолютними показаннями за бюджетні кошти : наказ МО3 від 10.07.2004 № 579 [Електронний ресурс]. - Режим доступу : https://zakon.rada.gov.ua/ laws/show/z0224-05

12. Прикарпатський центр репродукції людини [Електронний ресурс]. - Режим доступу : https://ecoif.com.ua/

13. WHO Infertility definitions and terminology [Електронний ресурс]. - Режим доступу : http://www.who.int/reproductivehealth/topics/infertility/definitions/en/

cines, which will be procured in 2019 under the budget program "Provision of methodological measures of individual state programs and complex measures of a programmatic nature". [Electronic resource]. Available from: /www.apteka.ua/article/478855. Ukrainian.

8. Medical Center Medicover. [Electronic resource]. Available from:: https://medicover.ua/uk. Ukrainian.

9. NICE Guidance Fertility problems: assessment and treatment. [Electronic resource]. Available from: https://www.nice.org.uk/guidance/cg156/chapter/ Recommendations\#investigation-of-fertility-problemsand-management-strategies. Ukrainian.

10. National List of Essential Medicines. [Electronic resource]. Available from: http://moz.gov.ua/ uploads/0/3799-nacperelic_dodatok_web.pdf. Ukrainian.

11. Order of the Ministry of Health №579 dated July 10, 2004 "On Approval of the Procedure for sending women for the first course of infertility treatment by methods of auxiliary reproductive technologies in absolute indications for budgetary funds" [Electronic resource]. Available from: https: //zakon.rada. gov.ua/laws/show/ z0224-05. Ukrainian.

12. Precarpathian Center for Human Reproduction [Electronic resource]. Available from: https://eco-if.com.ua

13. WHO Infertility definitions and terminology [Electronic resource]. - Available from: http://www.who.int/reproductivehealth/topics/infertility/definitions/en/

\section{Відомості про авторів:}

Стасів X.-О. Я. - аспірант, асистент кафедри організації і економіки фрармації, технології ліків та фрармакоекономіки ФПДО, Львівський національний медичний університет імені Данила Галицького, Львів, Україна. E-mail: khrystyna. stasiv6545@gmail.com, ORCID 0000-0003-4073-4327

Заліська О. М. - д. фрармац. н., професор, завідувач кафредри організації економіки фрармації, технології ліків та фармакоекономіки ФПДО, Львівський національний медичний університет імені Данила Галицького, Львів, Україна. E-mail: olzaliska@ukr.net, ORCID 0000-0003-1845-7909

Максимович Н. М. - канд. фрармац. н., старший викладач кафредри організації і економіки фрармації, технології ліків та фрармакоекономіки ФПДО, Львівський національний медичний університет імені Данила Галицького, Львів, Україна. E-mail: maximovi43@ukr.net, ORCID 0000-0003-0515-0385

ISSN 2312-0967. Фармацевтичний часопис. 2019. № 3 
Information about the authors:

Stasiv Kh.-O. Ya. - PhD student (Pharmacy), assistant of the Management and Economy of Pharmacy, Medicine Technology and Pharmacoeconomics Department, Postgraduate Faculty, Danylo Halytsky Lviv National Medical University, Lviv, Ukraine. E-mail: khrystyna.stasiv6545@gmail.com, ORCID 0000-0003-4073-4327

Zaliska O. M. - DS (Pharmacy), Professor, Chief of the Management and Economy of Pharmacy, Medicine Technology and Pharmacoeconomics Department, Postgraduate Faculty, Danylo Halytsky Lviv National Medical University, Lviv, Ukraine. E-mail: olzaliska@ukr.net, ORCID 0000-0003-1845-7909

Maksymovych N. M. - PhD (Pharmacy), Senior Lecture of the Management and Economy of Pharmacy, Medicine Technology and Pharmacoeconomics Department, Postgraduate Faculty, Danylo Halytsky Lviv National Medical University, Lviv, Ukraine. E-mail: maximovi43@ukr.net, ORCID 0000-0003-0515-0385 